\title{
PROGRAM FOR 2004 ANNUAL MEETING
}

\author{
30th Annual Meeting \\ June 23-26, 2004 \\ Wailea Marriott, Wailea, Maui, Hawaii \\ Preliminary Program
}

\author{
WEDNESDAY, JUNE 23, 2004 \\ 3:00 PM Registration Opens \\ 7:00 PM New Members Reception, Luau Gardens
}

THURSDAY, JUNE 24, 2004

6:00 АM
7:00 AM
$8: 00 \mathrm{AM}$
$8: 10 \mathrm{AM}$

9:10 AM

10:00 AM

10:30 AM
Samson Fun Run

Registration

Continental Breakfast-Exhibit Hall

Introduction of New Members and Resident Essay Finalists, Haku/Pikake Rooms

SCIENTIFIC SESSION (10 minutes presentation, 10 minutes discussion), Haku/Pikake Rooms Moderators: Vaughn A. Starnes and Robert C. Robbins

1. Coronary Artery Bypass Grafting Without Annuloplasty for Moderate Ischemic Mitral Regurgitation: Long-Term Outcomes, Multiphase Parametric Modeling, and Propensity Analysis

D. R. Wong, A. K. Agnihotri, J. W. Hung, G. J. Vlahakes, C. W. Akins, A. D. Hilgenberg, J. C. Madsen, T. E. Macgillivray, M. H. Picard, and D. F. Torchiana, Massachusetts General HospitalBoston, Mass

2. Multimodality Treatment of Unresectable Stage III Non-Small Cell Lung Cancer: Interim Analysis of an Ongoing Phase II Trial Using Preoperative Gemcitabine With Concurrent Radiotherapy

D. Galetta, ${ }^{a}$ A. Cesario, ${ }^{a}$ S. Margaritora, ${ }^{a}$ V. Porziella, ${ }^{a}$ R. M. D'Angelillo, ${ }^{\mathrm{b}}$ L. Trodella, ${ }^{\mathrm{b}}$ and P. Granone, ${ }^{a}$ Division of General Thoracic Surgery ${ }^{a}$ and Department of Radiotherapy, ${ }^{b}$ Catholic University-Rome, Italy

3. Complex Aortic Valve Repair Provides a Durable and Effective Alternative to Valve Replacement in Children With Aortic Valve Disease

J. S. Tweddell, P. C. Frommelt, A. N. Pelech, R. D. Jaquiss, K. A. Mussatto, and S. B. Litwin, Medical College of Wisconsin, Children's Hospital of Wisconsin-Milwaukee, Wis

PRESIDENTIAL ADDRESS

Vaughn A. Starnes, Los Angeles, Calif

Coffee Break-Visit Exhibits, Plumeria/Maile Rooms

SCIENTIFIC SESSION (10 minutes presentation, 10 minutes discussion), Haku/Pikake Rooms Moderators: Edward D. Verrier and R. Scott Mitchell

†4. Autologous Skeletal Myoblast Survival Correlates With Changes in Left Ventricular Remodeling in Dilated Ischemic Heart Failure P. I. McConnell, ${ }^{\mathrm{a}}$ C. del Rio, ${ }^{\mathrm{a}}$ M. Brunner, ${ }^{\mathrm{a}}$ V. Kushnir, ${ }^{\mathrm{a}}$ J. H. Dinsmore, ${ }^{\mathrm{b}}$ A. Zawadzka, ${ }^{\mathrm{b}}$ D. B. Jacoby, ${ }^{\text {}}$ P. Kwiatkowski, ${ }^{a}$ and R. E. Michler, ${ }^{\text {a }}$ The Ohio State University Medical Center-Columbus, Ohio, ${ }^{\mathrm{a}}$ and GenVec-Boston, Mass ${ }^{\mathrm{b}}$ 
5. Aortic and Mitral Valve Replacement and Reconstruction of the Intervalvular Fibrous Body in 82 Patients: An Analysis of the Clinical Outcomes

N. C. De Oliveira, T. E. David, S. Armstrong, and J. Ivanov, The Toronto General Hospital,

University of Toronto-Toronto, Ontario, Canada

6. In the Current Era Complete Revascularization Improves Survival Following Coronary Artery Bypass Surgery

T. Kleisli, W. Cheng, R. Kass, C. Blanche, G. Fontana, M. Jacobs, M. DeRobertis, J. Mirocha, and

A. Trento, Cedars-Sinai Medical Center-Los Angeles, Calif

†7. Completion Pneumonectomy for Chronic Mycobacterial Disease

J. T. Sherwood, J. D. Mitchell, and M. Pomerantz., University of Colorado Health Sciences CenterDenver, Colo

CONTROVERSIES IN THORACIC SURGERY

"Moderate Ischemic Mitral Regurgitation Should Always Be Repaired"

12:30 PM Adjourn

7:00 PM Ancient Polynesia Theme Dinner

Pacific Terrace

FRIDAY, JUNE 25, 2004

6:30 AM

A. Adult Cardiac Session

Awapuhi I \& II

Update on Robotically Assisted Cardiac Surgery

Vaughn A. Starnes

Manpower Issues: Physician Assistants' Roles

John C. Chen

B. General Thoracic Session

Puakenikeni I

Optimal Staging of Lung Cancer

Douglas E. Wood

Update on the Use of Chemotherapy for Resected Early Stage Lung Cancer

John D. Mitchell

C. Congenital Heart Disease Session

Puakenikeni II

Palliative Repair of HLHS: The Sano vs Norwood Procedure

Sano Procedure-TBA

Norwood Procedure-Winfield J. Wells

7:00 AM

8:00 AM

Continental Breakfast—Exhibit Hall, Plumeria/Maile Rooms

POSTGRADUATE COURSE

Sponsored by: White Memorial Medical Center and Foundation-Lyman A. Brewer, III Fund Haku/ Pikake Rooms

Introduced by: Vaughn A. Starnes

Guest Speaker: Norman E. Shumway, Stanford, Calif

$\dagger$ Samson Resident Prize Essay

1544 The Journal of Thoracic and Cardiovascular Surgery • May 2004 
8:50 AM SCIENTIFIC SESSION (10 minutes presentation, 10 minutes discussion), Haku/Pikake Rooms Moderators: John D. Mitchell and James I. Fann

8. Is Early Anticoagulation Necessary after Bioprosthetic Aortic Valve Replacement?

T. M. Sundt, K. J. Zehr, J. A. Dearani, R. C. Daly, C. J. Mullany, C. G. McGregor, F. J. Puga, T. A. Orszulak, and H. V. Schaff, Mayo Clinic-Rochester, Minn

†9. Annular or Subvalvular Approach to Chronic Ischemic Mitral Regurgitation?

F. Tibayan, ${ }^{\text {a }}$ F. Rodriguez, ${ }^{\mathrm{a}}$ F. Langer, ${ }^{\mathrm{a}} \mathrm{M}$. Zasio, ${ }^{\mathrm{a}}$ L. Bailey, ${ }^{\mathrm{a}}$ D. Liang, ${ }^{\mathrm{a}}$ G. Daughters, ${ }^{\mathrm{b}}$ N. Ingels, ${ }^{\mathrm{b}}$ and D. Miller, ${ }^{\mathrm{a}}$ Stanford University—Stanford, Calif, ${ }^{\mathrm{a}}$ and Palo Alto Medical Foundation-Palo Alto, Calif $^{b}$

10. The Accuracy of EUS and PET-CT in Restaging Patients With Esophageal Cancer After Neoadjuvant Chemoradiotherapy

R. J. Cerfolio, A. S. Bryant, and A. S. Bryant., University of Alabama at Birmingham-Birmingham, Ala

$\uparrow$ Evaluating COX-2 Inhibition in an Orthotopic Murine Model of Lung Cancer for DoseDependent Effect

E. M. Sievers, R. D. Bart, L. M. Backhus, C. A. DiPerna, R. Costanos, V. A. Starnes, and R. M. Bremner, Keck School of Medicine, University of Southern California-Los Angeles, Calif

12. Modern Surgical Treatment of Massive Pulmonary Embolism: Results in 43 Consecutive Patients Using a Combination of Rapid Diagnosis and Aggressive Surgical Approach M. Leacche, D. Unic, T. Mihaljevic, J. D. Rawn, S. Z. Goldhaber, L. H. Cohn, and J. G. Byrne, Brigham and Women's Hospital-Boston, Mass

$10: 30 \mathrm{AM}$

Coffee Break-Visit Exhibits, Plumeria/Maile Rooms

11:00 AM

SCIENTIFIC SESSION (10 minutes presentation, 10 minutes discussion), Haku/Pikake Rooms Moderators: David A. Bull and David A. Fullerton

13. Which Biological Valve Should We Select for the 45- to 65-Year-Old Age Patient Choosing a Biological Aortic Valve Replacement?

F. Dagenais, P. Mathieu, J. Perron, G. Raymond, J. Metras, R. Baillot, D. Desaulniers, and D. Doyle, Laval Hospital-Sainte-Foy, Quebec, Canada

$\dagger$ 14. Efficacy of Intraluminal Pulmonary Artery Banding

V. V. Piluiko, ${ }^{\text {a J. A. Poynter, }}{ }^{\text {b R. E. Delius, }}{ }^{\text {a }}$ R. Thomas, ${ }^{\text {a }}$ and H. L. Walters, ${ }^{\text {a }}$ Children's Hospital of Michigan-Detroit, Mich, ${ }^{a}$ and University of Michigan-Ann Arbor, Mich $^{\mathrm{b}}$

15. Randomized Trial of Open vs Endoscopic Vein Harvest for Coronary Artery Bypass Grafting (CABG): Six-Month Patency Rates

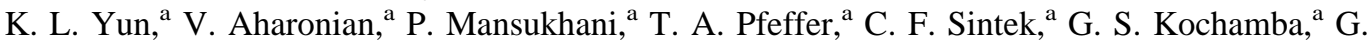
Grunkemeier, ${ }^{b}$ and S. Khonsari, ${ }^{a}$ Kaiser Permanente Los Angeles Medical Center-Los Angeles, Calif, ${ }^{\mathrm{a}}$ and Providence Health System-Portland, Ore ${ }^{\mathrm{b}}$

12:00 PM Adjourn

AFTERNOON-GOLF AND TENNIS TOURNAMENTS

EVENING-FREE

\section{SATURDAY, JUNE 26, 2004}

7:00 AM Continental Breakfast-Exhibit Hall, Plumeria/Maile Rooms

$7: 30 \mathrm{AM}$ POSTER FORUM SESSION (5 minutes presentation, 21/2 minutes discussion), Haku/Pikake Rooms Moderators: Robert C. Robbins and David A. Bull 
P1. A Vascularized Three-Dimensional Scaffold for Myocardial Infarct Repair

S. Kawamoto, ${ }^{a}$ R. B. Vernon, ${ }^{a}$ Q. Shi, ${ }^{a}$ M. D. Gooden, ${ }^{a}$ J. P. Flynn, ${ }^{a}$ Y. Tabata, ${ }^{\text {b }}$ and M. D. Allen, ${ }^{a}$ The Hope Heart Institute-Seattle, Wash, ${ }^{a}$ and Institute for Frontier Medical Sciences, Kyoto University-Kyoto, Japan ${ }^{\mathrm{b}}$

P2. The Mechanism of CD8 Lymphocyte Function in Chronic Rejection of Heart Transplants G. T. Schnickel, G. R. Hsieh, D. Whiting, J. J. Yun, W. Yao, M. C. Fishbein, A. Ardehali, and David Geffen, School of Medicine at UCLA, Los Angeles, Calif

P3. Inhibition of Toll-Like Receptor 4 With E5564 Attenuates Myocardial Ischemia-Reperfusion Injury

A. Shimamoto, ${ }^{\text {acc }}$ S. Kobayashi, ${ }^{b}$ A. J. Chong, ${ }^{a}$ H. Takayama, ${ }^{a}$ A. J. Fleisig, ${ }^{\text {a }}$ C. R. Hampton, ${ }^{a}$ C. L. Rothnie, ${ }^{a}$ D. J. Spring, ${ }^{\text {a }}$ T. H. Pohlman, ${ }^{a}$ and E. D. Verrier, ${ }^{a}$ University of Washington School of Medicine-Seattle, Wash, ${ }^{a}$ Eisai Research Institute-Wilmington, Mass, ${ }^{\mathrm{b}}$ and Mie University School of Medicine-Tsu, Japan ${ }^{\mathrm{c}}$

P4. Pharmacological Cerebral Capillary Blood Flow Improvement After Deep Hypothermic Circualtory Arrest: An Intravital Fluorescence Microscopy Study in Pigs

L. Ben Mime, ${ }^{\text {a }}$ S. Arnhold, ${ }^{\mathrm{b}}$ J. Easo, ${ }^{\mathrm{a}}$ J. H. Fischer, ${ }^{\mathrm{c}}$ G. Bennink, ${ }^{\mathrm{a}}$ E. R. de Vivie, ${ }^{\mathrm{a}}$ U. Mehlhorn, ${ }^{\mathrm{a}}$ and M. Suedkamp, ${ }^{\mathrm{a}}$ Cardiothoracic Surgery, ${ }^{\mathrm{a}}$ Department of Anatomy, ${ }^{\mathrm{b}}$ and Experimental Surgery, ${ }^{\mathrm{c}}$ University of Cologne-Cologne, Germany

P5. Growth of the Pulmonary Autograft: The Proof Is in Another Dimension F. G. Scholl, F. Wong, M. Mulloy, M. Ailawadi, P. Chang, A. Kavanaugh-McHugh, and D. C. Drinkwater, Vanderbilt University Medical Center-Nashville, Tenn

P6. New Technologies for Real Time Endoscopic Histologic Imaging in Thoracic Surgery Using Fiberoptic Optical Coherence Tomography M. Brenner, ${ }^{a}$ N. M. Hanna, ${ }^{a}$ D. Saltzman, ${ }^{a}$ D. Mukai, ${ }^{a}$ N. El-Abbadi, ${ }^{a}$ H. Beydoun, ${ }^{a}$ J. Milliken, ${ }^{b}$ W. Jung, ${ }^{a}$ S. Guo, ${ }^{a}$ and Z. Chen, ${ }^{a}$ University of California, Irvine, Beckman Laser Institute, and University of California, Irvine, Medical Center ${ }^{\mathrm{b}}$-Irvine, Calif

P7. Time-Resolved 3D Magnetic Resonance Velocity Mapping of Aortic Outflow in Volunteers and Patients After Valve-Sparing Aortic Root Replacement M. Markl, M. T. Draney, J. M. Levin, E. E. Williamson, N. J. Pelc, D. Liang, D. C. Miller, and R. J. Herfkens, Stanford University-Stanford, Calif

P8. Procedure Rates and Outcomes of Coronary Revascularization Procedures in California and New York

J. S. Carey, ${ }^{\text {a }}$ J. P. Gold, ${ }^{\mathrm{b}}$ S. J. Rossiter, ${ }^{\mathrm{a}}$ and B. Danielsen, ${ }^{\mathrm{c}}$ California Society of Thoracic Surgeons-Torrance, Calif, ${ }^{\mathrm{a}}$ Albert Einstein College of Medicine-Bronx, NY, ${ }^{\mathrm{b}}$ and Health Information Solutions-Sacramento, Calif ${ }^{\mathrm{c}}$

SCIENTIFIC SESSION (10 minutes presentation, 10 minutes discussion), Haku/Pikake Rooms Moderators: Richard I. Whyte and Robbin Cohen

$\dagger$ 16. Allopurinol/Uricase and Ibuprofen Enhance the Restorative Effect of Cardiomyocyte-Enriched, Human Embryonic Stem Cells Following Myocardial Injury T. Kofidis, ${ }^{a}$ R. Swijnenburg, ${ }^{a}$ D. R. Lebl, ${ }^{a}$ J. L. DeBruin, ${ }^{a}$ J. M. Greve, ${ }^{b}$ J. Gold, ${ }^{c}$ C. Xu, ${ }^{c}$ and R. C. Robbins, ${ }^{\text {a }}$ Stanford University Medical School, ${ }^{a}$ Stanford University Medical School/Department of Radiology ${ }^{\mathrm{b}}$ - Stanford, Calif, and Geron Corporation-Menlo Park, Calif ${ }^{\mathrm{c}}$

17. Treatment of High-Risk Patients With Non-Small Cell Lung Cancer Using Radiofrequency Ablation

H. C. Fernando, A. de Hoyos, R. J. Landreneau, M. Alvelo-Rivera, P. O. Buenaventura, N. A. Christie, P. F. Ferson, and J. D. Luketich, University of Pittsburgh-Pittsburgh, Pa 
18. Emergency Endovascular Interventions for Acute Thoracic Aortic Rupture: Four-Year Followup

M. Doss, J. Balzer, H. G. Fieguth, G. Wimmer-Greinecker, and A. Moritz, J. W. Goethe University Frankfurt-Frankfurt am Main, Germany

19. Cerebral Monitoring Using Transcranial Doppler Ultrasound Improves Neurologic Outcome During Repairs of Acute Type A Aortic Dissection

L. Estrera, Z. Garami, C. C. Miller, E. E. Porat, T. T. Huynh, R. Sheinbaum, B. S. Allen, and H. J. Safi, University of Texas at Houston Medical School, Memorial Hermann Hospital—Houston, Tex

9:50 AM

10:10 AM

$\uparrow 20$

$11: 10 \mathrm{AM}$

12:00 PM

$12: 30 \mathrm{PM}$

7:00 PM
Coffee Break-Visit Exhibits, Plumeria/Maile Rooms

SCIENTIFIC SESSION (10 minutes presentation, 10 minutes discussion), Haku/Pikake Rooms Moderators: John C. Chen and Douglas E. Wood

20. Adenosine A2A Receptor Activation Reduces Inflammation and Preserves Pulmonary Function in an In Vivo Model of Lung Transplantation

W. R. T. B. Reece, P. I. Ellman, T. S. Maxey, I. K. Crosby, P. S. Warren, T. Chong, J. Linden, J. A. Kern, C. G. Tribble, and I. L. Kron, University of Virginia-Charlottesville, Va

21. Bipolar Radiofrequency Ablation of Atrial Fibrillation

A. M. Gillinov, P. M. McCarthy, E. H. Blackstone, J. Rajeswaran, G. Pettersson, J. F. Sabik, L. G. Svensson, D. M. Cosgrove, G. Gonzalez-Stawinski, and F. Najam, The Cleveland Clinic Foundation-Cleveland, Ohio

22. Comparison of Standard Maze III and Radiofrequency Maze Operations for Treatment of Atrial Fibrillation

J. R. Doty, D. B. Doty, J. H. Flores, M. Mensah, K. J. Chan, B. B. Reid, S. E. Clayson, and R. C. Millar, LDS Hospital-Salt Lake City, Utah

C. WALTON LILLEHEI POINT/COUNTERPOINT SESSION, Haku/Pikake Rooms Atrial Fibrillation Ablation Should Be a Catheter-Based Procedure

ANNUAL BUSINESS MEETING (Members Only), Haku/Pikake Rooms

Luncheon, Luau Gardens

PRESIDENT'S RECEPTION AND BANQUET

Aulani Foyer and Ballroom

$†$ Samson Resident Prize Essay

\section{The American Board of Thoracic Surgery}

\section{Notices}

$\mathrm{T}$

The part I (written) examination will be held at the Sofitel Chicago O'Hare Hotel, Rosemont, Illinois, on November 21, 2004. The closing date for registration is August 1, 2004. Those wishing to be considered for examination must request an application since it is not automatically sent.

To be admissible for the Part II (oral) examination, a candidate must have successfully completed the Part I (written) examination.
A candidate applying for admission to the certifying examination must fulfill all the requirements of the Board in force at the time the application is received. Please address all communications to the American Board of Thoracic Surgery, One Rotary Center, Suite 803, Evanston, IL 60201 (telephone: 847-475-1520).

\section{Requirements for Recertification/Maintenance of Certification in 2004}

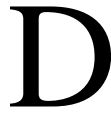
iplomates of the American Board of Thoracic Surgery who plan to participate in the Recertification/Maintenance of Certification process in 2004 must hold an active medical license and must hold clinical privileges in thoracic surgery. In addition, a valid certificate is an absolute requirement for 